\title{
Visual information processing of sequentially presented inputs: I. Effects of input timing on sub-span storage and retrieval mechanisms'
}

\author{
M. S. MAYZNER, ${ }^{2}$ M. E. TRESSELT, N. TABENKIN, R. DIDNER, AND M. S. HELFER ${ }^{3}$ \\ NEW YORK UNIVERSITY
}

A computer-based cathode-ray tube display system was employed to study the effect of subspan list length, i.e., two, three, or four five-letter words, and several interstimulus interval (ISI) values, i.e., 100, 150,200, 250, 300, 500, and $700 \mathrm{msec}$, on visual information processing. Complicated interactions were found between list length and ISI values. Two classes of Ss were identified and labeled as "slow" and "fast" processors and the overall findings were related to a provisional model of visual information processing with sequential inputs.

In 1964, in an address to the Canadian Psychological Association, Harold Schlosberg described a series of experiments concerned with the temporal aspects of serial visual perception. Schlosberg's (1965) address ${ }^{4}$ was subsequently published and provides one of the departure points of the present study. As Schlosberg (1965) remarks: "There is an impressive amount of evidence that two successive perceptual intakes must be separated by something of the order of $1 / 4$ or $1 / 3 \mathrm{sec}$ if both are to register. There are also interference effects at much shorter intervals. For example, a bright flash will blank out all the information presented in a dim exposure which came just before it. This phenomenon has been studied intensively by many workers since Crawford reported it in 1947 (see Raab, 1963). This backward blanking depends on the relative intensities of the two stimuli, and on the interval between them. However, even very bright blanking flashes show no backward effect beyond 50 or $100 \mathrm{msec}$. It should be noted that this situation differs from that in ordinary serial perception, as in reading, in two ways: (1) there is a great difference between the intensities of the two stimuli, and (2) reports are made only on the first stimulus, variously called test or information flash. Furthermore, most workers attribute the phenomenon to relatively peripheral factors. The most obvious suggestion is that the bright blanking flash has such a short latency that its effects catch up with those of the $\operatorname{dim}$ test flash, thus effectively washing out its effect in the Visual Cortex. In fact, Donchin, Wicke, and Lindsley (1963) have shown that this is what actually happens, by beautiful records of evoked potentials from the occipital lobe in man.

"In our own laboratory we were attempting to separate peripheral from the more central contributions--we were using two or three information flashes, of equal luminance and observing their mutual interaction, rather than the backward masking effect of a bright blanking flash on an earlier information flash. Thus we hoped to get at the time required for some central consolidation or processing of a unit of information [pp. 162-163]."

A second departure point for the present study derives from a series of papers by Mayzner and Tresselt and their associates (Greenberg, Helfer, \& Mayzner, in press; Mayzner, 1968; Mayzner \& Tresselt, 1966; Mayzner, Tresselt, \& Cohen, 1966; Mayzner, Tresselt, \& Helfer, 1967a, b; Mayzner, Tresselt, Adrignolo, \& Cohen, 1967). In these papers, visual information processing with sequential inputs has been systematically examined as a function of several input display parameters, employing a computer-based cathode-ray tube (CRT) display system.
The present study basically extends the Schlosberg technique which we have previously referred to as the "overprinting" of sequentially presented inputs (Mayzner, Tresselt, \& Helfer, 1967b). It also suggests how Schlosberg's concept of "central consolidation" might be incorporated into our present provisional model of visual information processing (Mayzner, Tresselt, \& Helfer, 1967b). The extension of Schlosberg's technique was made possible by the use of a computer-based CRT display system, which allows for the display of more than just two or three inputs, i.e., the values examined by Schlosberg, who employed a three-channel projection tachistoscope.

More specifically, two, three, or four five-letter words were displayed sequentially to $S$ with varying interstimulus interval (ISI) values, following Schlosberg's technique, and recall or retrieval of these various length input strings, at varying ISI values, was then immediately requested of $S$. We intentionally did not exceed four sequentially displayed inputs or words, as we were concerned with the effects of the above mentioned parameters (i.e., number of inputs or list length and ISI values) on visual information processing as it relates to subspan storage and retrieval mechanisms. In support of this position, George Miller (1956, p.92) has demonstrated that the immediate memory span for monosyllabic English words is about five (i.e., the "magic number" is seven plus or minus two). This value of five words, well within the immediate memory span capacity, also agrees with the results of an experiment of Crannell and Parrish (1957). Further, in selecting four inputs or words as our upper limit, it would appear that we are being especially conservative as Neisser (1967) has stated that immediate memory span has a roughly fixed capacity of seven unrelated words, while "many more than seven words can be recalled easily after one presentation if they form a sentence [p. 220]."

\section{Subjects}

\section{PRELIMINARY EXPERIMENT: EXPERIMENT 1}

Twenty undergraduate students selected randomly at the University Heights campus of New York University served as Ss.

\section{Apparatus}

The stimuli were presented on two Fairchild CRT display consoles simultaneously, both slaved to a 340 Master Display, driven by a PDP-7 digital computer. A complete description of this hardware system and its associated computer programs (software) may be found in our previous publications (Mayzner, 1968; Mayzner, Tresselt, \& Helfer, 1967a).

\section{Materials}

The stimulus materials consisted of 180 different high frequency five-letter words selected at random from the "AA" classification of the Thorndike-Lorge (1944) word lists. From these 180 words, 60 separate input word strings were generated, with each of the 60 word strings constituting a separate test trial for $\mathrm{S}$. Twenty strings were composed of two words, 20 strings were composed of three words, and 20 strings were composed of four words. Display luminance was 
approximately $1 \mathrm{~mL}$ for a steady-state display, as measured with a MacBeth illuminometer. $S$ was positioned $2 \mathrm{ft}$ in front of the display, with individual letter size $1 / 2 \mathrm{in}$. high and $3 / 8$ in. wide. Display "on" time per word was fixed at $10 \mathrm{msec}$ since extensive previous testing (Mayzner, Tresselt, \& Helfer, 1967b) had shown that $10 \mathrm{msec}$ provided more than ample time for $\mathrm{S}$ to report with complete accuracy a single five-letter word, under the conditions of individual letter size and display luminance described above.

\section{Procedure}

The input word strings were displayed before the $20 \mathrm{Ss}$, two Ss at a time, employing the two Fairchild display consoles. As indicated, there were 20 two-word strings, 20 three-word strings, and 20 four-word strings, and each set of these 20 word strings was further subdivided into four subsets, with each subset involving one of four different ISI values, i.e., 100, 300,500 , or $700 \mathrm{msec}$ between words in a given subset. The words in each word string were displayed to $S$ in exactly the same location on the Fairchild display consoles, thus employing the "overprinting" paradigm employed in previous studies (Greenberg, Helfer, \& Mayzner, in press; Mayzner, Tresselt, \& Helfer, 1967b), and is also identical with the procedure followed by Schlosberg (1965) in his study. Schlosberg also employed a value of $10 \mathrm{msec}$ "on" time per word.

The two major parameters of the study (i.e., length of input string or list length, consisting of two, three, or four words, and four different ISI values of $100,300,500$, and $700 \mathrm{msec}$ ) yield 12 different testing combinations, and with five trials per combination, a grand total of 60 test trials were generated and displayed to each of the 20 Ss of the preliminary experiment. A random order of these testing combinations was employed, so that on any given trial $\mathrm{S}$ might receive any length string at any given ISI value.

Subjects were given prepared answer forms on which they were to write down after each display presentation what they could recall, and they were told "ready" approximately $1 / 2 \mathrm{sec}$ before each display sequence was presented. To be scored correct, the correct word had to be recalled in its correct location in the input string, and the Ss were so instructed. Ample time was provided between each display sequence or trial for each $S$ to write down what he could recall of that particular display sequence. Illumination for this recall procedure was provided by a bank of lights in the ceiling of the testing room, which were on during the entire testing session, and in no way interfered with the quality of the image on the CRT display console.

\section{Results and Discussion}

The results of this preliminary experiment (Experiment 1) are presented in Fig. 1 and show the mean per cent correct recall for the $20 \mathrm{Ss}$ of the study as a function of the number of words in the input string (i.e., two, three, or four) for the four ISI values (i.e., $100,300,500$, or $700 \mathrm{msec}$ ) that were examined. It is obvious from an examination of Fig. 1 (for $\mathrm{N}=20$ ) that ISI values of 300,500 , and $700 \mathrm{msec}$ yield almost identical straight-line mean per cent correct recall functions, while an ISI value of $100 \mathrm{msec}$ produces radically different recall performance, and appears to be a linear decreasing function of list length.

Since the results of Fig. 1 show that for a list length of only two words, with an ISI value of $100 \mathrm{msec}$, recall performance is only $52 \%$, a marked discrepancy between these results and those obtained in an earlier study (Greenberg, Helfer, \& Mayzner, in press) has occurred, where with two five-letter words with an "on" time of $10 \mathrm{msec}$ and ISI value of $100 \mathrm{msec}$, recall performance was a little over $90 \%$ for the two Ss that were tested. As a result of this discrepancy, the range

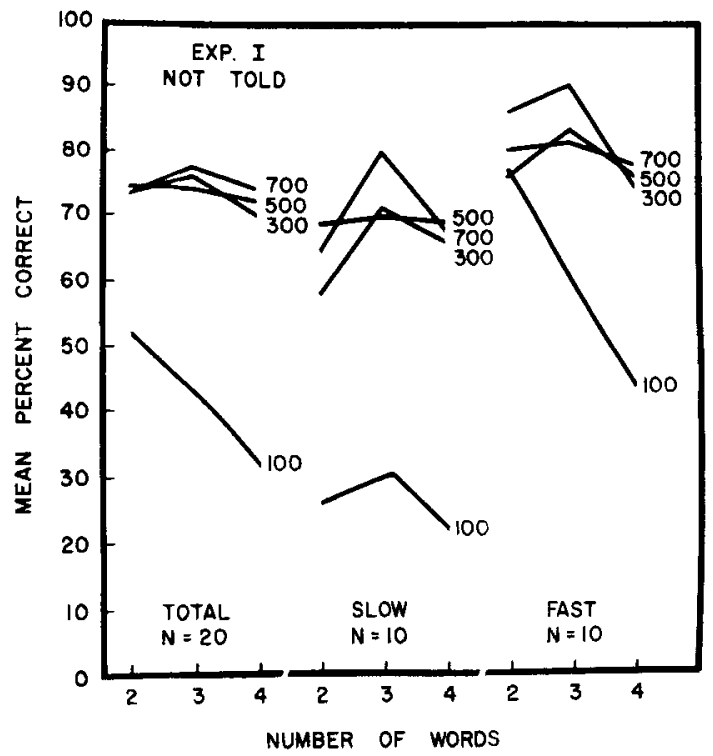

Fig. 1. Mean per cent correct recall as a function of list length for four ISI values.

of recall scores for the 20 Ss tested in this study was examined for this particular testing combination (i.e., 10-100-10 msec), and it was found that the individual scores ranged from a low of $10 \%$ correct recall to a high of $90 \%$ correct recall, with three Ss, in fact, obtaining scores of $90 \%$ correct recall. It was decided therefore to cut this range of 20 scores at the median, and those 10 Ss falling below the median were labeled "slow" processors, while the $10 \mathrm{Ss}$ falling above the median were labeled "fast" processors. Recall scores were then recalculated for all testing combinations based on this breakdown and are also plotted in Fig. 1. These results strongly suggest that little difference occurs between "slow" and "fast" processors for ISI values of 300,500 , and $700 \mathrm{msec}$, but markedly different functions exist at an ISI value of $100 \mathrm{msec}$, as list length varies from two to four words. The results also resolve the discrepancy between the earlier study and the present study, if one assumes that the two Ss used in the earlier study, and selected at random, happened by chance to be "fast" processors.

\section{Subjects}

\section{MAIN EXPERIMENT: EXPERIMENT 2}

Forty undergraduate students selected randomly at the University Heights campus of New York University served as Ss. None of these $40 \mathrm{Ss}$ had participated in Experiment 1 of this study.

\section{Apparatus}

The apparatus for Experiment 2 was identical to that used in Experiment 1.

\section{Materials}

The stimulus materials consisted of the 180 different high frequency five-letter words of Experiment 1, plus an additional 45 "AA" words, for a grand total of 225 different "AA" words. Letter size, display luminance, display "on" time, etc., were identical to Experiment 1 . The 225 words employed were randomly divided into 25 two-word strings, 25 three-word strings, and 25 four-word strings.

\section{Procedure}

A 2 by 3 by 5 mixed ANOVA design was employed (Winer, 1962, pp. 324-328). Factor A (two levels) consisted of 


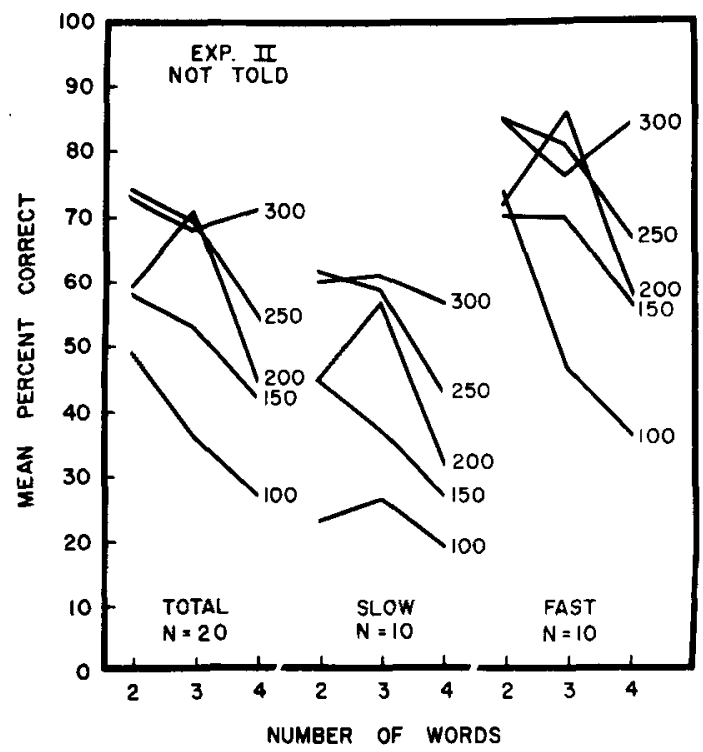

Fig. 2. Mean per cent correct recall as a function of list length for five ISI values for Ss not told of list length.

instructing 20 of the 40 Ss employed, prior to the presentation of each word string, the number of words (i.e., two, three, or four) that would be displayed to them; the actual words were, of course, not disclosed to them, just the number that would be displayed. The remaining $20 \mathrm{Ss}$ received no such instructions, and knew only that on any given trial they might receive either two, three, or four words. Again the "overprinting" paradigm was employed as in Experiment 1. Factor B (three levels) consisted of the length of the input word string or list length, i.e., either two, three, or four words. Factor $C$ (five levels) consisted of the different ISI values employed, i.e., 100, 150, 200, 250, and $300 \mathrm{msec}$. The three levels of Factor B combined with the five levels of Factor C yield 15 different test combinations (i.e., repeated measurements were obtained on Factors $B$ and $C$ ), and as in Experiment 1, five trials per test combination were employed, yielding a grand total of 75 test trials per $S$. These 75 test trials were randomly ordered, as in Experiment 1. Recall performance and scoring was also identical to the procedures used in Experiment 1.

\section{Results}

The major results of Experiment 2 are presented in Figs. 2 and 3 and Table 1 . Figures 2 and 3 show the mean per cent correct recall for the $40 \mathrm{Ss}$ of the study, as a function of the number of words in the input string (i.e., two, three, or four) for the five ISI values (i.e., 100, 150, 200, 250, or $300 \mathrm{msec}$ ) that were examined, for the "not told" and "told" conditions, respectively. Since per cent correct recall scores were employed as the dependent response measure, an inverse sine transformation was applied to the raw scores prior to the ANOVA, as recommended by Edwards (1968, p. 109). The ANOVA showed clearly that Factor A (i.e., "not told" vs "told") was modestly significant $(F=4.16, \quad$ df $=1 / 38$, $\mathrm{p}<.05$ ), while Factors B (list length) and C (ISI values) were highly significant $(F=34.9, \mathrm{df}=2 / 76, \mathrm{p}<.001 ; \mathrm{F}=90.1$, $\mathrm{df}=4 / 152, \mathrm{p}<.001)$, and one interaction term, $\mathrm{B}$ by $\mathrm{C}$, was also significant $(F=7.68, \mathrm{df}=8 / 304, \mathrm{p}<.001)$. These results are clearly in line with the functions shown in Figs. 2 and 3 (for $\mathrm{N}=20$ ), where it is obvious that for all list lengths and ISI values, the "told" Ss recall more than the "not told" Ss, the average improvement for all 15 testing combinations being $10.3 \%$. Further, it is also very evident that as list length increases from two to four words, mean per cent correct recall drops, in general, while as ISI values increase, from 100 to $300 \mathrm{msec}$, mean per cent correct recall rises. Similar to Experiment 1, the $20 \mathrm{Ss}$ in each of the "not told" and the "told" conditions were divided into "slow" and "fast" processors, and these results are also plotted in Figs. 2 and 3. Again, the same trends found in Fig. 1 (Experiment 1), for ISI values of 100 and $300 \mathrm{msec}$, are clearly evident in both Figs. 2 and 3 (Experiment 2).

In Table 1, which presents the per cent correct recall by serial position for all conditions in Experiments 1 and 2, certain trends may be clearly observed. For example, for the two-word strings, per cent correct recall is always superior in Serial Position 2 in contrast to Serial Position 1, for all conditions in both experiments. For three-word strings, for ISI values of either 100 or $150 \mathrm{msec}$, a typical serial position U-shaped function may be seen which is not present for ISI values of $200,250,300,500$, and $700 \mathrm{msec}$. Also, for four-word strings for ISI values of either 100, 150, or $200 \mathrm{msec}$, a U-shaped function may be seen which is not present for ISI values of $250,300,500$, and $700 \mathrm{msec}$. A breakdown was also made for "slow" and "fast" processors and the same trends shown in Table 1 are again found for these two subgroups, with, of course, the "fast" processors showing superior recall performance over the "slow" processors for all testing combinations examined.

\section{DISCUSSION}

In a previous paper (Mayzner, Tresselt, \& Helfer, 1967b) a provisional model of visual information processing with sequential inputs was outlined. Very briefly, the model suggested that when visual inputs (whose "on" time varies from $50 \mu \mathrm{sec}$ to approximately $50 \mathrm{msec}$ and are clearly above threshold) enter the visual system they pass through a succession of information or data processing components, i.e., visual receptor mechanisms, visual cortex, higher centers (central storage), a gating mechanism, and finally arrive after approximately $130 \mathrm{msec}$ of real-time input processing at a component we have called "subjective visual experience" (SVE). This component represents the S's actual subjective visual experience associated with any given visual input which is above threshold and whose "on" time varies from $50 \mu \mathrm{sec}$ to approximately $50 \mathrm{msec}$. Further, we estimated input pro-

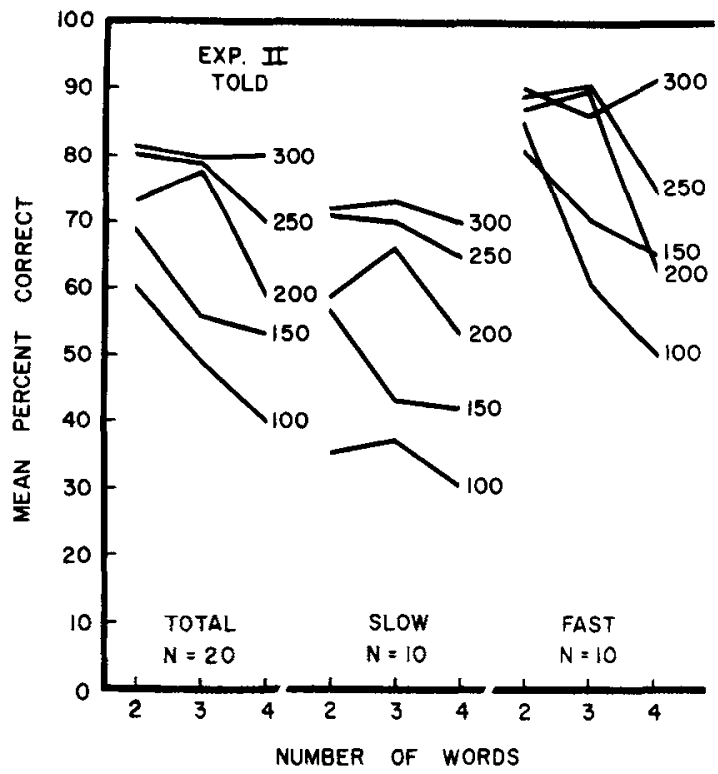

Fig. 3. Mean per cent recall as a function of list length for five ISI values for Ss told of list length. 
Table 1

Percent Correct Recall for Serial Position Analysis $(\mathrm{N}=\mathbf{2 0})$

\begin{tabular}{|c|c|c|c|c|c|c|c|c|c|c|}
\hline & & $2-W$ & Id String & & 3-Word & String & & & lord & String \\
\hline & ISI & 1 & 2 & J & 2 & 3 & 1 & 2 & 3 & 4 \\
\hline Experiment 1 & $100 \mathrm{msec}$ & 43 & 60 & 40 & 35 & 58 & 53 & 35 & 14 & 27 \\
\hline & $300 \mathrm{msec}$ & 68 & 76 & 73 & 80 & 79 & 71 & 69 & 71 & 72 \\
\hline Not Told & $500 \mathrm{msec}$ & 72 & 73 & 69 & 82 & 78 & 58 & 85 & 76 & 71 \\
\hline & $700 \mathrm{msec}$ & 70 & 74 & 74 & 81 & 84 & 72 & 73 & 73 & 74 \\
\hline Experiment 2 & $100 \mathrm{msec}$ & 45 & 52 & 36 & 29 & 43 & 48 & 22 & 10 & 29 \\
\hline & $150 \mathrm{msec}$ & 57 & 58 & 54 & 44 & 61 & 48 & 45 & 31 & 42 \\
\hline Not Told & $200 \mathrm{msec}$ & 55 & 62 & 57 & 70 & 85 & 62 & 36 & 30 & 51 \\
\hline & $250 \mathrm{msec}$ & 68 & 79 & 62 & 73 & 75 & 51 & 45 & 63 & 60 \\
\hline & $300 \mathrm{msec}$ & 65 & 80 & 62 & 70 & 74 & 65 & 69 & 73 & 75 \\
\hline Experiment 2 & $100 \mathrm{msec}$ & 45 & 75 & 40 & 38 & 70 & 52 & 30 & 16 & 62 \\
\hline & $150 \mathrm{msec}$ & 65 & 73 & 55 & 52 & 61 & 55 & 53 & 38 & 67 \\
\hline Told & $200 \mathrm{msec}$ & 68 & 78 & 70 & 75 & 88 & 71 & 54 & 42 & 67 \\
\hline & $250 \mathrm{msec}$ & 68 & 92 & 62 & 83 & 91 & 65 & 69 & 67 & 79 \\
\hline & $300 \mathrm{msec}$ & 72 & 90 & 64 & 85 & 89 & 73 & 87 & 79 & 82 \\
\hline
\end{tabular}

cessing time in SVE to be on the order of approximately $100 \mathrm{msec}$. We suggested that visual inputs once having passed through SVE may enter a "rehearsal loop" which feeds into the central storage component of the model, and where subsequent retrieval mechanisms operate on the inputs making them available for verbal report.

A more recent paper (Greenberg, Helfer, \& Mayzner, in press) tested certain features of our provisional model, and-relevant to the present study-two five-letter words were presented in an "overprinting" paradigm for different "on-off" time combinations. For the two Ss tested, it was found that for the 10-100-10 msec condition, recall performance was above $90 \%$ correct recall, and, in fact, the $10-50-10 \mathrm{msec}$ condition was also above $90 \%$ correct recall; however, correct recall dropped to about $60 \%$ for the $10-25-10 \mathrm{msec}$ condition and to about $20 \%$ for the $10-10-10 \mathrm{msec}$ condition. From these and other results obtained in the study, it was concluded that if two sequential inputs were separated in time by about $50 \mathrm{msec}$ or less, marked interference occurred between the two inputs, either prior to or in the SVE component of the model, yielding very poor recall; if $50 \mathrm{msec}$ or more separated the two inputs, little interference would occur.

The results of the present study would now strongly suggest that the time separation between two sequentially presented inputs required for minimal or zero interference probably varies considerably from $S$ to $S$, as the breakdown of "slow" vs "fast" processors clearly shows in Figs. 1, 2, and 3 (which represent three independent replications of this effect). This result represents the first major finding of the present study and indicates that future work, concerned with interference effects between two or more inputs as a function of ISI values, may be seriously in error if such individual difference factors are not taken into consideration.

One of the major objectives of the present study was to expand on Schlosberg's (1965) work. Figs. 1, 2, and 3 clearly show that Schlosberg's conclusion that "for the kind of organization that goes on in even simple reading the inputs must be separated by about $300 \mathrm{msec}$ [p. 172] " (using two or three sequentially presented inputs), also applies to the use of four inputs, since with two, three, or four inputs, essentially straight-line functions are obtained for ISI values of 300,500 , or $700 \mathrm{msec}$. Figures 2 and 3 , which examine ISI values between 100 and $300 \mathrm{msec}$, show clearly that certain processing operations must take place in this time domain, particularly as the number of inputs is increased from two to four, as evidenced by the significant interaction term in the ANOVA between ISI values and list length. More specifically, Figs. 2 and 3 show that the effect of ISI varies complexly as a function of the number of inputs in the input string. With four inputs, each additional $50 \mathrm{msec}$ of ISt between 100 and $300 \mathrm{msec}$ increases the mean per cent correct recall scores in a fairly linear fashion, while with either three or two inputs, each additional $50 \mathrm{msec}$ of ISI does not produce uniform increases in mean per cent correct recall scores, as may be seen in Figs. 2 and 3. The above observations also apply to the results obtained with the "slow" processors: however, with the "fast" processors, a very different pattern or ordering of the mean per cent correct recall scores occurs for each additional $50 \mathrm{msec}$ of ISI, for all list lengths examined. For example, in the "told" condition of Experiment 2. for two inputs, for the "fast" processors, mean per cent correct recall varies from only 81 to $90 \%$, while for the "slow" processors, the equivalent range is from 35 to $74 \%$. This would seem to indicate that "fast" processors have essentially no difficulty in processing two inputs where ISI values vary from 100 to $300 \mathrm{msec}$, while "slow" processors have considerable difficulty, and each additional $50 \mathrm{msec}$ of ISI is generally helpful in improving their information processing capacity. However, as soon as list length is increased from two to three or four inputs, the effect of ISI values changes dramatically. For example, with three or four inputs, an ISI value of $100 \mathrm{msec}$ yields an essentially straight-line function for the "slow" processors, while for the "fast" processors, a very steep decreasing linear function is found, and this is true for both the "told" and "not told" conditions of Experiment 2.

The differences in the shape of these two functions found at an ISI value of $100 \mathrm{msec}$ and, in addition, the changes in shape which occur between 100 and $300 \mathrm{msec}$ for the "slow" and "fast" processors, as seen in Figs. 1, 2, and 3, indicate, we believe, the following implications for our provisional model.

For "slow" processors an ISI value of $100 \mathrm{msec}$, with either two, three, or four inputs, is of sufficiently short duration so that marked interference between successive sequentially presented inputs occurs prior to or in SVE; as a result, these inputs do not arrive at the central storage component of the model, via the "rehearsal loop," sufficiently intact for subsequent retrieval. As each additional $50 \mathrm{msec}$ of ISI is added, additional processing time becomes available and the shapes of the functions for "slow" and "fast" processors become similar. In contrast, for the "fast" processors, an ISI value of $100 \mathrm{msec}$ with just two sequentially presented inputs provides ample time for processing prior to or in SVE; thus no interference effects develop and subsequent retrieval from central storage is quite good. However, if three or four sequentially presented inputs are separated by only $100 \mathrm{msec}$ for the "fast" processors, then marked decrements in retrieval occur. This finding would seem to indicate that since two inputs show no interference effects and retrieval is excellent, 
while three or four inputs produce marked decrements in retrieval, the difficulty with three and four inputs arises in the central storage component of the model.

Speculating further along these lines, we should like to offer the following argument, which may be most clearly noted for the "fast" processors of the "told" condition of Experiment 2 , although the "fast" processors of the "not told" condition of Experiment 2 show similar results. Let us assume, for the "fast" processors of the "told" condition of Experiment 2, that for two inputs, variations in ISI values between 100 and $300 \mathrm{msec}$ have no effect on recall performance, the actual range varying only between 81 and $90 \%$ correct recall. If we assume further that the slight departure from $100 \%$ correct recall is due to random eye blinking effects-since "on" time was only $10 \mathrm{msec}$-then $100 \%$ correct recall is not an unreasonable estimate. With three inputs, ISI values of 300 , 250 , and $200 \mathrm{msec}$ continue to show almost perfect recall, the actual range varying only between 86 and $91 \%$ correct recall; however, with an ISI value of $150 \mathrm{msec}$ correct recall decreases to $70 \%$ and with an ISI value of $100 \mathrm{msec}$ correct recall decreases still further to $60 \%$. Moving on to four inputs, only an ISI value of $300 \mathrm{msec}$ yields almost perfect recall. Thus, with two inputs, essentially perfect recall results with ISI values ranging from 100 to $300 \mathrm{msec}$; with three inputs, essentially perfect recall results with ISI values ranging from 200 to $300 \mathrm{msec}$; and with four inputs, essentially perfect recall results only with an ISI value of $300 \mathrm{msec}$. In other words, for each additional input added above two inputs, an additional $100 \mathrm{msec}$ of ISI is needed to maintain essentially perfect recall. We tentatively conclude therefore-and this represents the second major finding of the study-that Schlosberg's "central consolidation" time, i.e., the time required for "trace information" to occur in the central storage component of our model so that subsequently presented sequential inputs will not interfere with this "consolidation or trace formation" process, is on the order of $100 \mathrm{msec}$. We would further argue that this "consolidation or trace formation" time of $100 \mathrm{msec}$ may also hold for the "slow" processors, but its estimate from the "slow" processors recall functions is not directly deducible because of the complicating interference effects which occur at the more peripheral levels of the visual system for the "slow" processors, i.e., interference effects prior to or within the SVE component of the model.

The serial position data shown in Table 1, which constitutes the third major finding of this study, demonstrates clearly the differential effects of ISI values on recall performance. Most important, the typical U-shaped serial position curve, almost always found with the recall of supraspan input strings, also appears with subspan input strings if ISI values are sufficiently small; and further, this value varies by $50 \mathrm{msec}$ between the three- and four-word strings. These serial position results suggest that whatever storage and retrieval mechanisms produce U-shaped functions with supraspan lists and which disappear with subspan lists (if sufficiently high ISI values are employed, i.e., approximately $250 \mathrm{msec}$ or above for four-word strings and approximately $200 \mathrm{msec}$ or above for three-word strings) will reappear again if ISI drops below some critical value. Since this critical ISI value differs for the threeand four-word strings, we tentatively would argue that the underlying storage and retrieval mechanisms responsible for U-shaped serial position functions involve complex trade-offs between list length and ISI values. Thus, if ISI values are low enough to produce interference effects in "consolidation or trace formation" processes, a subspan list length of only three or four inputs will yield the typical U-shaped serial position curve. To state the position in a slightly different way; one can overload the storage and retrieval system either by increasing list length or by decreasing ISI values, and either type of overloading will produce a $\mathrm{U}$-shaped serial position curve.
Finally, the fourth major finding of this study, that the average $10 \%$ increase in recall scores found as a function of prior instructions to $S$ as to how many inputs will be presented, would seem to indicate that even in the processing of the minimum number of inputs that can be presented sequentialiy (namely two), higher-order mechanisms of "set," "expectancy," or perhaps "specially tuned attentional mechanisms" can have significant effects on input processing and its subsequent storage and retrieval. All four major findings of this study would seem to indicate that further modifications or expansions will be required in our provisional model (Mayzner, Tresselt, \& Helfer, 1967b) concerning: (1) "slow" vs "fast" processors, (2) establishing with greater certainty that "central consolidation" or "trace formation" time is on the order of $100 \mathrm{msec}$, (3) explicitly treating serial position effects and their interaction with list length and ISI values, and (4) incorporating into the model the effects of "specially tuned attentional mechanisms" (this task will be pursued in later papers).

The four major findings just outlined also have some relevance to the recent theorizing of several investigators currently working in this general area of visual information processing. In particular, we have reference to the work of Eriksen and Collins (1968), Melton (1963), Neisser (1967), Schiller (1966), Sperling (1967), and White (1963). While we certainly do not intend to suggest that the work of these several investigators are all concerned with exactly the same problem area, a single thread does tie their work together in the sense that, in one way or another, all are concerned with sequential information processing.

Eriksen and Collins (1968) have studied the integration of form perception over time by presenting two sequential random dot patterns which, if ISI is sufficiently small, are integrated into a single composite three-letter nonsense syllable. Melton (1963) has provided a penetrating analysis of STM vs LTM, which has a direct bearing on our subspan technique. Neisser (1967) has suggested that the concept of "iconic storage" is central to sequential information processing. Sperling (1967) has proposed a model for short-term memory which involves an input signal consisting of five letters followed sequentially in time by a noise field. Schiller (1966) has studied forward and backward masking of pairs of sequentially presented letters. White (1963) has examined the processing of a string of light flashes varying the number of flashes presented and their rate of presentation.

In general, we would argue that the Schlosberg technique, which has been extended in the present study, and the four major findings that have accrued from this study would need to be explicitly treated by the theorizing of the above investigators. More specifically, in the theoretical positions now taken by Eriksen and Collins, Melton, Neisser, Sperling, Schiller, and White, it would appear that accommodation will need to be made for one or more of the following factors: (1) "slow" vs "fast" processors, (2) estimation of "central consolidation" or "trace formation" time, (3) the interaction of serial position effects with list length and ISI values, and (4) "specially tuned attentional mechanisms."

\section{REFERENCES}

CRANNELL, C. W., \& PARRISH, J. M. A comparison of immediate memory span for digits, letters, and words. Journal of Psychology, 1957, 44, 319-327.

DONCHIN, E., WICKE, J. D., \& LINDSLEY, D. B. Cortical evoked potentials and perception of paired flashes. Science, 1963, 141, 1285-1286.

EDWARDS, A. L. Experimental design in psychological research. (3rd ed.) New York: Holt, Rinehart, \& Winston, 1968.

ERIKSEN, C. W., \& COLLINS, J. F. Sensory traces versus the psychological moment in the temporal organization of form. Journal of Experimental Psychology, 1968, 77. 376-382. 
GREENBERG, M., HELFER, M. S., \& MAYZNER, M. S. Information processing of letter and word pairs as a function of on and off times. Perception \& Psychophysics, in press.

MAYZNER, M. S. The research potential of a computer-based cathode-ray tube display system. Behavior Research Methods \& Instrumentation, 1968, 1, 41-43.

MAYZNER, M. S., \& TRESSELT, M. E. Studies in sequential perception: Looking at one thing but finding another. Perceptual \& Motor Skills, 1966, 23, 257-258.

MAYZNER, M. S., TRESSELT, M. E., \& COHEN, A. Preliminary findings on some effects of very fast sequential input rates on perception. Psychonomic Science, 1966, 6, 513-514.

MAYZNER, M. S., TRESSELT, M. E., \& HELFER, M. S. A research strategy for studying certain effects of very fast sequential input rates on the visual system. Psychonomic Monograph Supplements, 1967a, 2 (5, Whole No. 21), 73-81.

MAYZNER, M. S., TRESSELT, M. E., \& HELFER, M. S. A provisional model of visual information processing with sequential inputs. Psychonomic Monograph Supplements, 1967b, 2 (7, Whole No. 23), 91-108.

MAYZNER, M. S., TRESSELT, M. E., ADRIGNOLO, A. J., \& COHEN, A. Further preliminary findings on some effects of very fast sequential input rates on perception. Psychonomic Science, 1967, 7, 281-282.

MELTON, A. W. Implications of short-term memory for a general theory of memory. Journal of Verbal Learning \& Verbal Behavior, 1963, 2, 1-21.

MILLER, G. A. The magical number seven, plus or minus two: Some limits on our capacity for processing information. Psychological Review, 1956, 63, 81-97.

NEISSER, U. Cognitive psychology. New York: Appleton-CenturyCrofts, 1967
RAAB, D. H. Backward masking. Psychological Bulletin, 1963, 60 118-129.

SCHILLER, P. H. Forward and backward masking as a function of relative overlap and intensity of test and masking stimuli. Perception \& Psychophysics, 1966, 1, 161-163.

SCHLOSBERG, H. Time relations in serial visual perception. Canadian Psychologist, 1965, 6a, 161-172.

SPERLING, G. Successive approximations to a model for short-term memory. Acta Psychologica, 1967, 27, 285-292.

THORNDIKE, E. L., \& LORGE, I. The teacher's word book of 30,000 words. New York: Teachers College, Columbia University, Bureau of Publications, 1944.

WHITE, C. T. Temporal numerosity and the psychological unit of duration. Psychological Monographs, 1963, 77 (12, Whole No. 575), 1-37.

WINER, B. J. Statistical principles in experimental design. New York: McGraw-Hill, 1962.

\section{NOTES}

1. This research was supported by Grant No. GB-8037 from the National Science Foundation, to the first author.

2. Address: 15 Sydney Avenue, Deal, New Jersey 07723.

3. Dr. M. S. Helfer is now with the IBM Thomas J. Watson Research Center, Yorktown Heights, New York 10598.

4. Dr. Robert Sekuler very kindly brought this paper to our attention and prepared Dr. Schlosberg's address for publication.

(Accepted for publication November 18, 1968.) 